\title{
Spatial Relation of Bumblebees (Hymenoptera-Apidae) with Host-Plant and their Conservation Issues: An Outlook from Urban Ecosystem of Kathmandu Valley, Nepal
}

${ }^{1}$ Central Department of Zoology, Tribhuvan University, Kirtipur, Nepal Corresponding author E-mail:drbhusal@cdztu. edu.np

${ }^{2}$ Birendra Multiple Campus, Chitwan, Tribhuvan University, Nepal

3 Himalayan Biodiversity Network-Nepal, Chitwan, Nepal

${ }^{4}$ Central Department of Environmental Science, Tribhuvan University, Kirtipur, Nepal

\author{
Daya Ram Bhusal $^{1 *}$, Kishor Chandra Ghimire $^{1,2}$, Sabina Dulal ${ }^{3}$, Pratikshya Baniya ${ }^{3}$, Sudeep Thakuri ${ }^{4}$
}

\begin{abstract}
Ecology and conservation status of bumblebee species remains poorly understood, especially in rapidly degrading urban ecosystems, which is important considering the role of bumblebees in the pollinations. We collected more than 200 bumblebee (Bombus spp.) specimens under six species in different parts of the Kathmandu valley (Kathmandu, Lalitpur, and Bhaktapur cities) in Nepal. The species of bumblebees were analyzed with their host plant types and the land use change using remote sensing and field observation data. We found that the bumblebees exert strong variation and were significantly affected by the families of the host plants and the nature of flowers (open and closed type) rather than colors and categories (invasive and noninvasive). We underline that the rapid habitat loss by changing land use in the study area can be a potential threat to the conservation of these important pollinators, and thus, need focused habitat conservation efforts.
\end{abstract}

KEYWORDS

Abundance, pollination, hostplants, land use, conservation

(cc)BY-NC-ND $\odot 2019$ Michal Ferenc et al.

This is an open access article distributed under the Creative Commons Attribution-NonCommercial-NoDerivs license

\section{INTRODUCTION}

Bumblebees are pollinators of many flowers that have high thermoregulatory abilities and are able to be active even at very low ambient temperatures (Miller-Struttmann et al., 2014; Corbet et al., 1993). Thus, they serve as important pollinators, especially in an alpine ecosystem (Yu et al., 2012). They are pollinators for many cultivated fruits, vegetables and spices, hence making them economically important. In recent years, dramatic declines of bumblebees have been reported in many parts of the world (Cameron et al., 201; Goulson et al., 2010; Potts et al., 2010; Williams and Osborne 2008) probably related to climate change, habitat lost, pathogens and land use change (Jacobson et al., 2018; Kerr et al., 2015; Rasmont et al., 2015; Cameron et al., 2011; Faeth et al., 2011).

The potential ecological consequences of urbanization in bumblebees, especially invasive plants, color of host plants and land use change are not well understood. Many studies have suggested that urbanization may result in some important ecological consequences, such as habitat loss for many pollinators with increasing urbanization (Neil and $\mathrm{Wu}$, 2006; Geslin et al., 2013). It is known that the decline of host plants is linked with the parallel decline of pollinators in response to land use change (Weiner et al., 2014; Goulson et al., 2010; Potts et al., 2010; Williams and Osborne, 2008). The growing urbanization has change the land use pattern, habitat quality and availability of host plant for bumblebees leading to the negative impact in urban ecosystem and sustainable ecosystem service (Gunnarsson and Federsel, 2014; Jha et al., 2013; Carvell et al., 2011; Potts et al., 2010; Biesmeijer et al., 2006). Bumblebees use flower traits, such as odor, shape, size and color to locate pollen-nectar sources therefore discriminate different flower species (Reverte, 2016; Dotterl et al., 2014; Chittka and Raine, 2006). Similarly, there is a rapidly growing impact of invasive alien plants on native insect pollinators including bees and bumblebees. Such impacts are likely to vary according to the taxon of host plant, the functionality 
of pollinators across ecosystem context (Bezemer et al., 2014). More field-based studies are needed to elucidate this issue under the current global change scenario.

This study assessed the bumblebees (Bombus) and their foraging plants, explored the response of bumblebees on host plants and also analyzed the land use change of study area to envision the possible consequences on its bumblebee fauna.

\section{MATERIALS AND METHODOLOGY}

\subsection{Study area}

This study was focused in the Kathmandu Valley $\left(27^{\circ} 32^{\prime} 13^{\prime \prime}\right.$ to $27^{\circ} 49^{\prime} 10^{\prime \prime} \mathrm{N}$ latitude and $85^{\circ} 11^{\prime} 31^{\prime \prime}$ to $85^{\circ} 31^{\prime} 38^{\prime \prime}$ E longitude). The area covers the four major cities (Kathmandu, Kirtipur, Lalitpur and Bhaktapur) of Nepal.

\subsection{Sample collection and identification}

The species survey was conducted extensively from April 2017 to November 2018 in different locations of the Kathmandu valley. Accessible walking trail in different habitat was considered to collect the bumblebees. The specimens were collected by the sweeping net method. Coordinate of bumblebee collection points were recorded, the host plant of the bumblebees, and the flower color, family, category (invasive/noninvasive) and the nature of flowers (open and close) of those foraged plants were observed and recorded. Finally, the collected bumblebees were kept in the refrigerator $\left(-4^{\circ} \mathrm{C}\right)$ to preserve them. After that, the specimens were dry-mounted on standard insect pins for identification.

\subsection{Specimen identification}

Specimens were identified using the published identification keys for the Himalaya region from Kashmir to Nepal (Williams et al., 2010), and India (Saini et al., 2015). The collected bumblebees were observed in a stereoscopic microscope under different magnifications (10x, 20x, and 40x). Similarly, food plants were also identified up to family level. The collected specimens were deposited in the Entomological Museum of the Central Department of Zoology, Tribhuvan University, Kirtipur.

\subsection{Data analysis}

Analysis of variance (ANOVA) with frequency of bumblebees, color of flowers, category (invasive and noninvasive plants), and families of host plant from the sampling points was performed. Similarly, our data were analyzed by applying generalized linear mixed effect model (GLMM) with the negative binomial distribution to find the effect of natures, categories and families of host plants. We considered the nature (close and open ) of flowers as the random effect in the distribution of bumblebees. Similarly, non-matrix multidimensional scaling (NMDS) was used to ordinate the relation of host plant families and bumblebee species with distance based (bray) meta-MDS dissimilarity function from the vegan package in R-software.

\subsection{Land use change analysis}

Land use data of 2000 and 2010 were compared and the trends of land use changed in Kathmandu valley was examined. The land use classes were obtained from the previous land use data of Nepal, derived from the REDD Implementation Cell, Ministry of Forest and Soil Conservation (http://mofsc-redd.gov. $\mathrm{np} /$ ). To evaluate the classification performance, the outputs of the Geographic Information System analysis were compared with the field observation and the high resolution Google Earth imagery.

\section{RESULTS}

\subsection{Abundance of bumblebees in study sites}

In this study, 525 bumblebee specimens were collected representing six species of the bumblebees. We found that the highest individual abundance was Bombushaemorrhoidalis and the least abundance was $B$. trifasciatus (Fig. 1). We observed these bumblebees from 11 host plant families having six flower colors. We analyzed the effect categories, nature, color and families of flowers of species of bumblebees (Table 1). The families and natures of host plants were significantly affected, but we found no significant effect with categories and colors of flowers in abundance of bumblebees in our study.

\subsection{Relative frequency of bumblebees with colors types of host plants}

The relative frequency of bumblebees with the color of flowers was also analyzed (Fig. 2). The highest variation of all six species was represented from the yellow-colored flowers and the

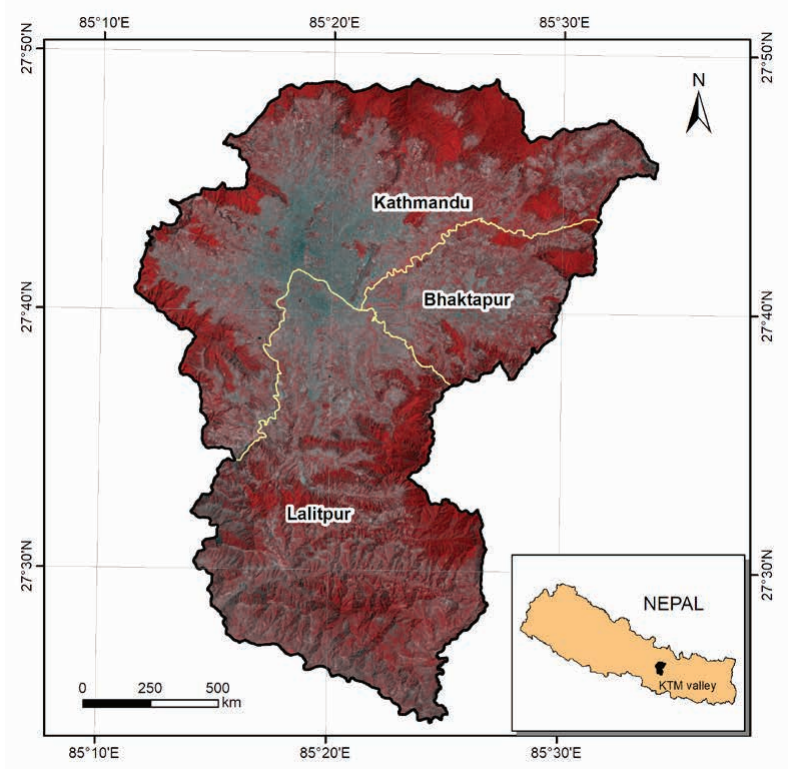

Figure 1. Map of Study area: A false color composite image of Kathmandu valley based on Landsat Imagery (vegetation is represented by red color). Inset map showing the location of Kathmandu valley in Nepal. 
Table 1. Analysis of variance (ANOVA) with frequency of bumblebees, color of flowers, category (invasive and noninvasive plants), and families of host plant from the sampling points

\begin{tabular}{c|c|c|c}
\hline Factors & Sum Sq. & df & F-test \\
\hline categories & 40.3 & 1 & 2.5084 \\
\hline nature & 38.3 & 1 & 2.406 \\
\hline color & 131.1 & 6 & 1.3607 \\
\hline family & 265.1 & 9 & 1.8352 \\
\hline
\end{tabular}

lowest variation of bumblebees presented in the blue-colored flowers.

\subsection{Effect of host plant types on bumblebees}

We implied Generalized linear mixed effect model (McFadden's pseudo $\mathrm{R}^{2}=0.312$ ), with the negative binomial distribution (AIC $=14.7)$ to find the effect of natures, categories and families of host plants (Table 1). We performed random effects test (Var = -1.21 and $S D=-0.0011$ ) of the nature of flowers. There is a significant effect of nature (open and close) and different families of host flower, but not categories (invasive and non-invasive host plant, as shown in Table 2). Similarly, we performed non matrix multidimensional scaling (NMDS) to ordinate the relation of host plant families and bumblebees' species. We used distance based (bray stress $=0.05$ ) meta-MDS dissimilarity function (Fig. 3).

\subsection{Land use change analysis of Kathmandu valley}

A total of 100 random points were generated (Fig. 5) from the satellite-based classified image and the points were overlaid and evaluated from the Google Earth image. Overall, the classification efficiency was more than $88 \%$. The possible impact of land-use changes (Table 3 ) in the natural habitats of bumblebees and the possible change of their relevant host plant types can be evaluated, especially declining status of agriculture land $(-5 \%)$ and forest area $(-3 \%)$ and grassland $(-19 \%)$. The major host plant families documented in this study were recorded specifically from forest, farmlands, and grassland habitats.

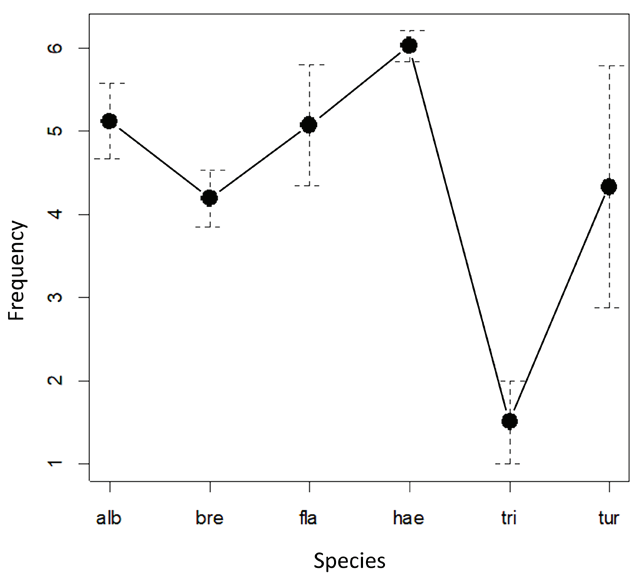

Figure 2. Mean abundance of Bumblebee species (B. haemorrhoidalis (hae), B. albopleuralis (alb), B. breviceps (bre), B. flavescens (fla), B. trifasciatus (tri), B. turneri (tri) in the sampling sites

\section{DISCUSSION}

In this study, B. haemorrhoidalis was the most widely and commonly visited species of local flora (Fig. 2); similar behavior was obtained in the eastern as well as western Himalaya (Sinu et al., 2011) and explained as a significant pollinator in these landscapes. The variation in distribution in different locations with different flora showed diverse floral host range for collection of nectar and pollens of this species (Nagano et al., 2014). The species richness and abundance of bumblebees are significantly affected by types of flower resources, indicating that there is a strong association of bumblebees with families of host plants across the study area. Many explanations have pointed out how flora characters such as morphology, color and scent are associated with the attraction of the bee communities (Stone et al., 2003, Cnaani et al., 2006; Fornoff et al., 2017). Elliott (2009) resulted the relation of foraging distances, bumblebee and flower availability (Williams and Osborne, 2009) indicated that species richness of bumblebee depends on increasing flower cover and the type of host plant and their richness compared to the other factors. The floral resources are the factors that alter the species richness, species diversity and abundance of the bumblebees (Potts et al., 2010). The reduction in species richness, evenness and abundance of the bumblebee is due to habitat fragmentation and reduction in the floral resources (Goulson et al., 2008; Xie et al., 2008), but Inouye (1980) studied the effect of morphological characters such as corolla length and of proboscis on the rate of flower visitation by bumblebees where short-tongued bees foraged faster on short-corolla flowers than long-tongued bees. In our study, the differential significant effect of plant families and

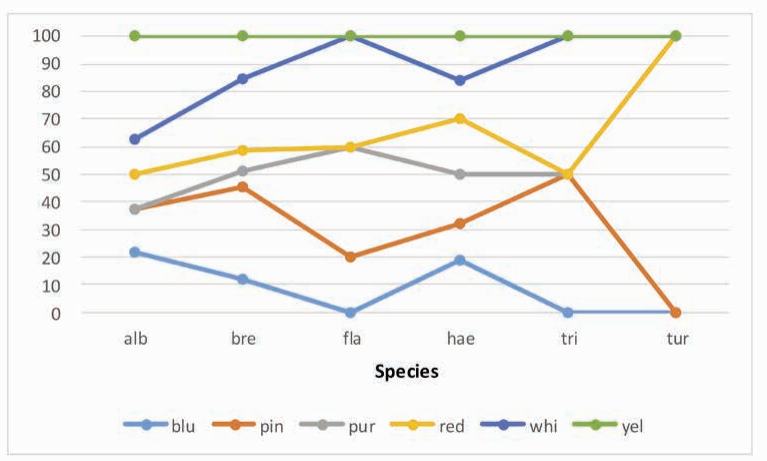

Figure 3. Relative frequency of the collected Bombus spp. in different flower color: Blue (blu), Pink (pin), Purple (pur), Red (red), White (whi), Yellow (yel) 
Table 2. Summary of the Generalized linear mixed effect model (GLMM) about the effect of natures, categories, and families of host plant with frequency of bumblebees. Relation of Natu (open-OP, close-CL), Categ (Invasive-IN, Non-Invasive -NI) and Families of host plants: Cannaceae (Can), Cucurbitaceae (Cuc), Solanaceae (Sol), Asteraceae (Ast), Malvaceae (Mal), Convolvulaceae (Con), Lamiaceae (Lam), Verbenaceae (Ver), Balsaminaceae (Bal), Rosaceae (Ros), Fabaceae (Fab), Iridaceae (Iri).

\begin{tabular}{c|c|c|c|c}
\hline Fixed effect: Variables & Estimate & Std. error & $z$-test & $p$-value \\
\hline (Intercept) & 1.79112 & 0.15283 & 11.719 & $\mathbf{2 . 0 0 E - 1 6}$ \\
\hline Natu (OP) & -0.5857 & 0.34709 & -1.687 & 0.05152 \\
\hline Categ (NI) & 0.11144 & 0.08456 & 1.318 & 0.18756 \\
\hline Fam (Bal) & -0.51626 & 0.4718 & -1.094 & 0.27385 \\
\hline Fam (Can) & 0.25867 & 0.41428 & 0.624 & 0.53237 \\
\hline Fam (Con) & 0.42506 & 0.35233 & 1.206 & 0.22764 \\
\hline Fam (Cuc) & 0.4059 & 0.42223 & 0.961 & 0.33639 \\
\hline Fam (Fab) & 0.22378 & 0.21706 & 1.031 & 0.30257 \\
\hline Fam (Iri) & 0.88036 & 0.61941 & 1.421 & 0.15524 \\
\hline Fam (Lam) & 1.03451 & 0.41773 & 2.477 & $\mathbf{0 . 0 1 3 2 7}$ \\
\hline Fam (Mal) & 0.58026 & 0.46285 & 1.254 & 0.20997 \\
\hline Fam (Ros) & -0.0641 & 0.57807 & -0.111 & 0.9117 \\
\hline Fam (Sol) & 1.05471 & 0.3829 & 1.735 & $\mathbf{0 . 0 0 5 8 8}$ \\
\hline Fam (Ver) & 0.5791 & 0.33381 & $\mathbf{0 . 0 5 2 7 7}$ \\
\hline
\end{tabular}

Table 3. Land use change in the Kathmandu valley from 2000 to 2010

\begin{tabular}{|c|c|c|c|c|c|c|}
\hline Class & $\begin{array}{c}\text { Landuse } 2000 \\
\left(\mathrm{~km}^{2}\right)\end{array}$ & $\%$ Coverage & $\begin{array}{c}\text { Landuse2010 } \\
\left(\mathrm{km}^{2}\right)\end{array}$ & $\%$ Coverage & Change $\left(\mathrm{km}^{2}\right)$ & $\%$ change \\
\hline Forest & 425.5 & 47 & 412.7 & 46 & -12.7 & -3 \\
\hline Shrubland & 1.6 & 0 & 0.6 & 0 & -1.0 & -62 \\
\hline Grassland & 21.8 & 2 & 17.5 & 2 & -4.2 & -19 \\
\hline Agriculture & 309.0 & 34 & 294.6 & 33 & -14.4 & -5 \\
\hline Barren land & 1.6 & 0 & 2.0 & 0 & 0.4 & 27 \\
\hline Water & 1.1 & 0 & 0.9 & 0 & -0.3 & -24 \\
\hline Settlement & 139.7 & 16 & 171.9 & 19 & 32.2 & 23 \\
\hline
\end{tabular}

nature of flowers (Table 1) on the abundance of bumblebees is probably associated with the specific floral characters of that particular family and nature of flowers. No statistically significant effect of categories of host plants (invasive and noninvasive) were observed in the study, especially for the abundance species of bumblebee.

The bumblebee species were found foraging abundantly in non-invasive categories of plants, while the invasive species, L. camera, was found as a continuous floral resource during the study period. The families, Cucurbitaceae, Fabaceae, and Verbenaceae were the most visited families by the bumblebee. This study has no significant effect on the color of flowers for the abundance of bumblebees, however, there are great variations of bumblebee frequencies with color types of a par- ticular flower (Fig. 3) indicating the differential color preference by bumblebee species in the area. Raine and Chittka (2005) explained the color preferences of the bumblebee (Bombus) in relation to the foraging performance and fitness. They concluded significant variation in their unlearned preference for violet over blue flowers. The blue color attracts more flower visitors due to the high amount of sugar availability (Dyer and Chittka, 2004) in the blue color than other flowers. The highest abundance as well as the high preference of bumblebee was observed in the blue color flowers due to the presence of high rewards (nectar) in the blue color flowers. Similarly, Lunau et al. (1996) studied the color choices of bumblebees and their implications for color perception. Similarly, Giurfa et al. (1995, 1996) carried out a research on color preferences of flower na- 


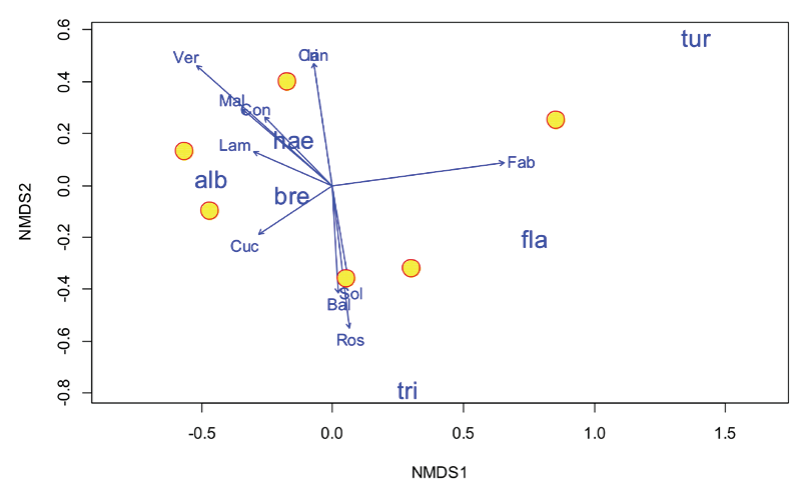

Figure 4. Non-matrix multidimensional scaling (NMDS) between the bumblebee species and the host families Cannaceae (Can), Cucurbitaceae (Cuc), Solanaceae (Sol), Asteraceae (Ast), Malvaceae (Mal), Convolvulaceae (Con), Lamiaceae (Lam), Verbenaceae (Ver), Balsaminaceae (Bal), Rosaceae (Ros), Fabaceae (Fab), Iridaceae (Iri)

ive bees. They concluded that bumblebee prefer colors of high color purity. The landscape context and the habitat quality influence the species composition of bumblebee (Carvell et al., 2011). Myczko et al. (2015) examined the flower color choice such as purple or white in Corydalis cava where they found that bumblebee queens and bumblebees differ in their choice of flower color.

Recent scenario of land use change from 2000 to 2010 (Fig. 5) indicated the rapid change in land use pattern that has resulted in the rapid expansion of urban area, which is the challenging for the conservation of natural habitat and
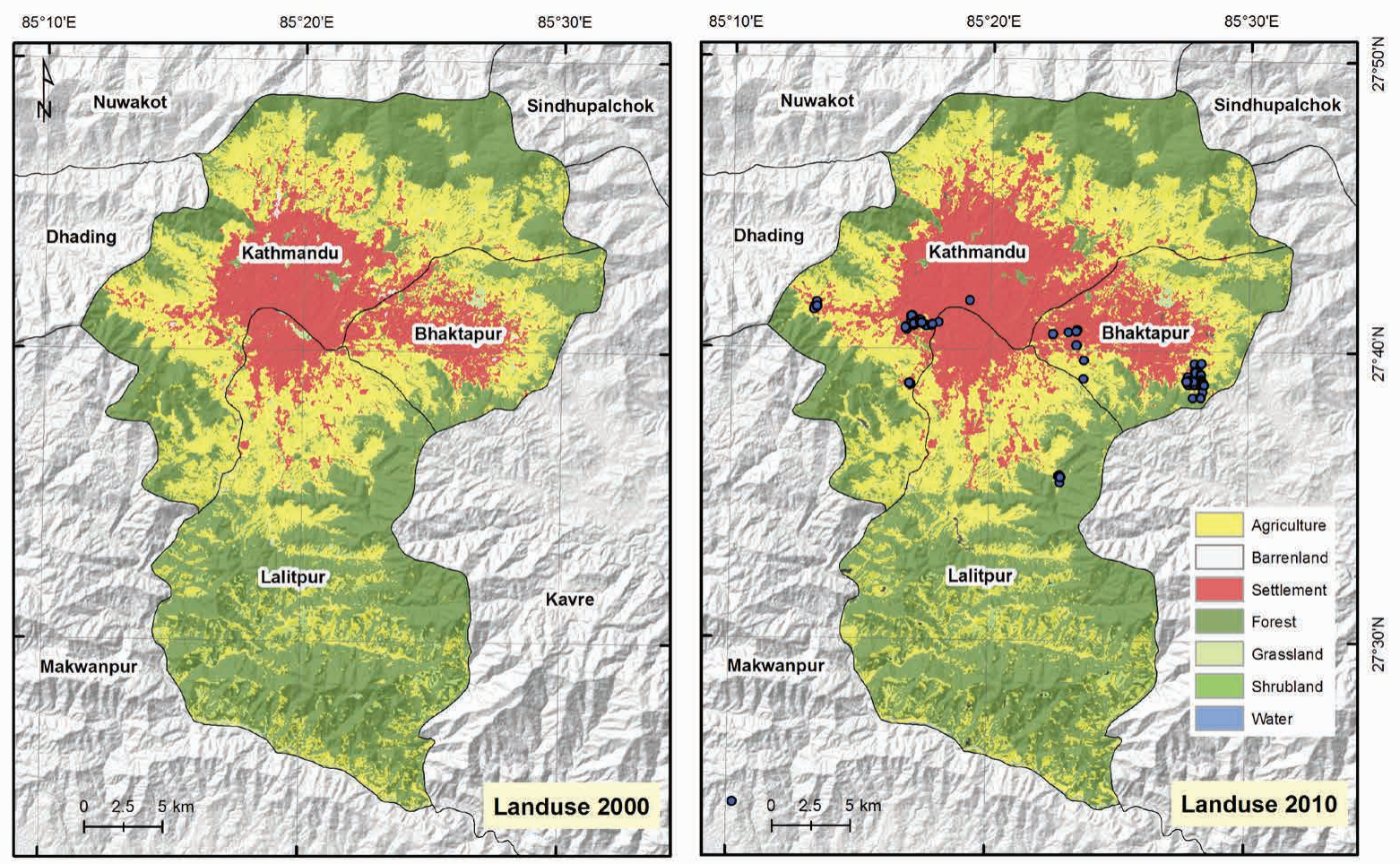

urban agro-ecosystem (Table 3) for many insect pollinators. If this trend of decline in agriculture and other natural habitat in Kathmandu valley continues in future, it can be expected that there will be a huge loss of urban pollinators, including bumblebees that especially depends upon the agri-based host plants such as leguminous and solaneceae. Land-use changes may be having a negative effect through reductions in food plants in many parts of the world (Weiner et al., 2014; Potts et al., 2010; Grixti et al., 2009; Williams and Osborne, 2009). Similarly, the effect of urbanization on plant pollinator interaction is poorly documented, however, few studies suggested an adverse effect on plant-pollinator interactions. These studies suggested a negative effect of urbanization with some herbivore groups and some pollinators (Geslin et al., 2013). Loss of habitat and fragmentation due to rapid urbanization are major threats to the conservation of bumblebees in many parts of the world. Many studies have shown that the urbanization effects on structure and communities of insects, resulting vast changes in their abundance and richness (Grimm et al., 2008; Raupp et al., 2010; Gardiner et al., 2014). The understanding and the exploration of bumblebees' host plant dynamics in the present urban habitats may help conservationists for planning sustainable conservation strategies as shown in other parts of the world (Faeth et al., 2011).

In conclusion, Kathmandu valley is probably attributed to a decline in its floral resources - growing urbanization, land use changes and changes in habitat might be the possible threats. Our result highlighted the importance of some host plants for the conservation of bumblebee in this rapidly urban-

Figure 5. Land-use change in the Kathmandu valley from 2000 to 2010 
izing valley. The diversity and morphology of floral resources are the major limiting factors in the species richness and distribution of bumblebees in the study area rather than specific color and categories (invasive and noninvasive) of the particular host plant. The gradual land use change of Kathmandu valley and the possibility of reduction of potential food plants has highlighted the need for sustainable conservation of these important pollinators, including bumblebees. These findings highlight that the abundance and diversity of bumblebees is sensitive to increasing urbanization that provides new clues to improve conservation measures in this rapidly urbanizing site. Therefore, the conservation of local floral resources via Promo- tion of urban park and design of relevance pollinator management strategies are the important recommendations of our research work.

Acknowledgements: This project is partially supported by $\mathrm{Hi}-$ malayan Biodiversity Network (HBN-Nepal) for field expenses to co-authors. Dr. Jiaxing Haung (CAAS, Beijing, China) provided much valuable information and kindly identified the voucher specimens in the Central Department of Zoology, TU, Nepal. We thank to Plant Taxonomists (Central Department of Botany, TU) and National Herbarium, Godawari, Lalitpur for the identification of host plants.
Bezemer, T.M., Harvey, J.A., Cronin, J.T. (2014) Response of native insect communities to invasive plants. Annual Review of Entomology, 59:119-141

Biesmeijer, J.C., Robert S.P.M., Reemer, M. (2006) Parallel declines in pollination and insect pollinated plants in Britain and Netherlands. Science, 313(5787):351-354

Cameron, S.A., Lozier, J.D., Strange, J.P., Koch, J.B., Cordes, N., Solter, L.F., Griswold, T.L. (2011) Patterns of widespread decline in North American bumble bees. Proc Natl AcadSci, 108:662-667

Carvell, C., Osborne, J. L., Bourke, A. F. G., Freeman, S. N., Pywell, R. F. \& Heard, M. S. (2011). Bumble bee species' responses to a targeted conservation measure depend on landscape context and habitat quality. Ecological Applications, 21(5), 1760-1771.

Chittka, L., Raine, N.E. (2006) Recognition of flowers by pollinators. Current Opinion in Plant Biology, 9(4):428-435

Cnaani, J., Thomson J.D., Papaj, D.R. (2006) Flower choice and learning in foraging bumblebees: effects of variation in nectar volume and concentration. Ethology, 112(3):278-285

Corbet, S.A., Fussell, M., Ake, R., Fraser, A., Gunson, C., Savage, A., Smith, K. (1993) Temperature and the pollinating activity of social bees. Ecological Entomology, 18(1):17-30

Dotterl, S., Gluc,k U., Jurgens, A., Woodring, J., Aas, G. (2014) Floral reward, advertisement and attractiveness to honey bees in dioecious Salix caprea. PloS one, 9(3), e93421

Dyer, A.G., Chittka, L. (2004) Fine colour discrimination requires differential conditioning in bumblebees. Naturwissenschaften, 91(5):224-227

Elliott, S.E. (2009) Subalpine bumble bee foraging distances and densities in relation to flower availability. Environmental Entomology, 38(3);748-756

Faeth, S.H., Bang, C., Saari, S. (2011) Urban biodiversity: Patterns and mechanisms. Ann N Y AcadSci, 1223:69-81. Doi: https://doi. org/10.1111/j. 1749-6632.2010. 05925.x

Fornoff, F., Klein, A.M., Hartig, F., Benadi, G., Venjakob, C., Schaefer, H.M., Ebeling, A. (2017) Functional flower traits and their diversity drive pollinator visitation. Oikos, 126(7):1020-1030

Gardiner, M.M., Prajzner, S.P., Burkman CE, Albro S, Grewal PS (2014) Vacant land conversion to community gardens: influences on generalist arthropod predators and biocontrol services in urban greenspaces. Urban Ecosyst, 17:101-122. Doi: https://doi. org/10.1007/ s11252-013-0303-6

Geslin, B., Gauzens, B., Thebault, E., Dajoz, I. (2013) Plant pollinator networks along a gradient of urbanisation. PloS one, 8, e63421

Goulson, D., Lepais, O., O'Connor, S., Osborne, J.L., Sanderson, R.A., Cussans, J., Darvill. B. (2010) Effects of land use at a landscape scale on bumblebee nest density and survival. Journal of Applied Ecology, 47(6):1207-1215

Grimm, N.B., Faeth, S.H., Golubiewski, N.E., Redman, C.L., Wu, J., Bai, X., Briggs, J.M. (2008) Global change and the ecology of cities. Science, 319(5864):756-760

Grixti, J.C., Wong, L.T., Cameron, S.A., Favret, C. (2009) Decline of bumble bees (Bombus) in the North American Midwest. Biological Conservation, 142:75-84

Gunnarsson, B., \&Federsel, L. M. (2014). Bumblebees in the city: abundance, species richness and diversity in two urban habitats. Journal of Insect Conservation, 18(6), 1185-1191

Jacobson, M.M., Tucker, E.M., Mathiasson, M.E., Rehan, S.M. (2018) Decline of 410 bumble bees in northeastern North America, with special focus on Bombusterricola. BiolConserv, 217:437445

Jha, S., \&Kremen, C. (2013). Urban land use limits regional bumble bee gene flow. Molecular Ecology, 22(9), 2483-2495.

Kerr, J.T., Pindar, A., Galpern, P., Packer, L., Potts, S.G., Roberts, S.M., Rasmont, P., Schweiger, O., Colla, S.R., Richardson, L.L., Wagner, D.L., Gall, L.F., Sikes, D.S., Pantotoja, A. (2015) Climate change impacts on bumblebees across continents. Science, 349:177180

Miller-Struttmann, N.E., Galen, C. (2014) High-altitude multi-taskers: bumble bee food plant use broadens along an altitudinal productivity gradient. Oecologia, 176:1033-1045

Myczko, L., Banaszak-Cibicka, W., Sparks, T. H., Tryjanowski, P. (2015) Do queens of bumblebee species differ in their choice of flower colour morphs of Corydalis cava (Fumariaceae)?. Apidologie, 46(3), 337-345.

Nagano, Y., Abe, K., Kitazawa, T., Hattori, M., Hirao, A.S., Itino, T. (2014) Changes in pollinator fauna affect altitudinal variation of floral 
size in a bumblebee-pollinated herb. Ecology and Evolution, 4:3395-3407

Neil, K., \& Wu, J. (2006). Effects of urbanization on plant flowering phenology: a review. Urban Ecosystems, 9(3), 243-257.

Potts, S.G., Biesmeijer, J.C., Kremen, C., Neumann, P., Schweiger, O., Kunin, W.E. (2010) Global pollinator declines: trends, impacts and drivers. Trends in Ecology \& Evolution, 25(6):345-353

Rasmont, P., Franzén, M., Lecocq, T., Harpke, A., Stuart, P.M.R., Biesmeijer, J., Castro, L., Cederberg, B., Dvorák, L., Fitzpatrick, U., Gonseth, Y., Haubruge, E., Mahé, G., Manino, A., Michez, D., Neumayer, J., odegaard, F., Paukkunen, J., Pawlikowski, T., Simon, G.P., Reemer, M., Settele, J., Straka, J., Schweiger, O. (2015) Climatic risk and distribution atlas of European bumblebees. BioRisk, 10:1-236

Raupp, M.J., Shrewsbury, P.M., Herms, D.A. (2010) Ecology of herbivorous arthropods in urban landscapes. Annual Review of Entomology, 55

Reverté, S., Retana, J., Gómez, J.M., Bosch, J. (2016) Pollinators show flower colour preferences but flowers with similar colours do not attract similar pollinators. Annals of Botany, 118:249-257
Rocha, E. A., Fellowes, M.D. (2018) Does urbanization explain differences in interactions between an insect herbivore and its natural enemies and mutualists? Urban Ecosystems, 21:405-417

Saini, M.S., Raina, R.H., Ghator, H.S. (2015) Indian Bumblebees. Bishen Singh 462 Mahendra Pal Singh, Dehra Dun, India

Sinu, P.A., Kuriakose, G., Shivanna, K.R. (2011) Is the bumblebee (Bombushaemorrhoidalis) the only pollinator of large cardamom in central Himalayas, India? Apidologie, 42:690-695

Stone, G.N., Raine, N.E., Prescott, M., Willmer, P.G. (2003) Pollination ecology of acacias (Fabaceae, Mimosoideae). Australian Systematic Botany, 16:103-118

Weiner, C.N., Werner, M., Linsenmair, K.E., Blüthgen, N. (2014) Land-use impacts on plant-pollinator networks: interaction strength and specialization predict pollinator declines. Ecology, 95:466-474

Williams, P.H., Ito, M., Matsumura, T., Kudo, I. (2010) The bumblebees of the Nepal Himalaya (Hymenoptera: Apidae). Insectamatsumurana. Series entomology. New series 66:115-151

Williams, P.H., Osborne, J.L. (2009) Bumblebee vulnerability and conservation world-wide. Apidologie, 40(3):367-387

Yu, W. B., LI, D. Z., \& Wang, H. (2012). Highly efficient pollination by bumblebees ensures seed production in Pedicularislachnoglossa (Orobanchaceae), an early-flowering Himalayan plant. Journal of Systematics and Evolution, 50(3), 218-226. 